\title{
A montagem cinematográfica como ato criativo
}

Maria Dora Genis Mourão Universidade de São Paulo 


\section{Resumo}

O foco deste trabalho é refletir sobre a montagem cinematográfica como ato criativo, não a montagem pensada como simples agenciadora de planos, mas como criadora de sentidos.

É na maneira como o cinema articula e aproxima as imagens e os sons que verificamos sua transformação em discurso. Criam-se novos sentidos, uma nova lógica onde os significados não são transparentes, nascida da associação de fragmentos. Justapõem-se duas realidades: a da vida propriamente dita e a do filme, a do discurso e, ainda dentro do filme, a justaposição de planos determinando novas leituras das imagens.

Partindo dos princípios da teoria da montagem cinematográfica de $\mathrm{S}$. M. Eisenstein, faremos um rápido panorama de como o cinema, no decorrer de sua história, foi influenciado pelos conceitos desenvolvidos em sua teoria.

\section{Palavras- Chave}

montagem. cinema. multicamadas. real do reflexo.

\section{Abstract}

The main objective of this article is to reflect on film editing regarded as a creative act: rather a sense-eliciting instance in filmmaking than the mere act of piecing footage together.

It is the manner in which filmmaking articulates and assembles images and sounds that makes films become discourse. New senses, a new logic is created, in which meanings are not transparent, since they are produced by the association of fragments. Two overlapping realities arise: on the one hand, the reality of life itself and, on the other, the film reality, ie the reality of discourse and, to remain within the film reality, the juxtaposition of images that determine new readings for these images.

Starting from the principles of S.M. Eisenstein's Film Editing Theory, this article presents a brief overview of how, along its history, cinema has been influenced by the concepts developed in Eisenstein's theory.

\section{Keywords}

film editing, multi-layer, reality of reflection 
"There was a period in our cinema when montage was proclaimed as being "everything". We are now coming to the end of a period when montage has been regarded as "nothing". Since we considered montage to be neither "nothing" nor

"everything", we now think it necessary to recall that montage is as essential a component of film-making as all the other affective elements of cinematography".

Montage 1938

S.M.Eisenstein

montagem cinematográfica não pode ser vista somente como
um procedimento técnico em que planos são combinados
com o único objetivo de traduzir o que está previsto no roteiro ou no pensamento do diretor. A montagem é essencial no processo de realização de um filme (ou de uma obra audiovisual) uma vez que é o momento em que se organizam os materiais e se define a estrutura da narrativa no jogo que se instaura na associação de imagens e sons. Vista como um momento de criação ela se impõe e passa a ter um papel central e significativo.

A proposta de S.M. Eisenstein, realizador russo atuante entre os anos 20 e 40 e teórico do cinema, de pensar a montagem como um dos elementos essenciais do filme, nos dá as pistas necessárias para entender seu pensamento considerado como um modelo paradigmático para a reflexão sobre montagem na medida em que ele soube reunir o ato reflexivo e $o$ ato criativo tendo como objetivo $o$ desenvolvimento de uma teoria da montagem cinematográfica, pois, para este cineasta, o cinema é uma "arte genuinamente sintética, uma arte da síntese orgânica em sua própria essência".

O cinema nos é apresentado por ele como uma arte impura, já que se constrói a partir das relações com outras formas de arte constituindo-se em uma síntese qualitativa delas. Nessa perspectiva, ele resgata a figura da montagem como necessidade estética e também 
ideológica, diante da situação que se impõe de organizar esses códigos heterogêneos com o objetivo de transformá-los em um novo meio de expressão artístico - o cinema - Isto é, tira o cinema da esfera da simples ação e do simples divertimento, como ocorria no início de sua história, e o coloca na esfera das idéias. É por isso que a montagem, pensada de maneira mais ampla, ou seja, para além do corta-cola, pode ser considerada como a base para pensar e fazer cinema.

Partindo do pressuposto de que o cinema sempre caminhou em paralelo e simultaneamente entre duas vertentes - a representação da realidade (com a aproximação com o referente) e a do artifício que refaz ou perturba esse referente tornando-o um imaginário -, é importante verificar como essas questões se colocam no decorrer da história do cinema e como as propostas de montagem de Eisenstein, definindo sua própria posição de linguagem diante dessas opções, influenciam a produção cinematográfica e audiovisual até hoje.

\section{As origens do cinema}

Apontar para as origens do cinema adotando um modelo de pensamento não linear nos permitirá recuperar momentos em que o cinema deu passos importantes na demonstração do papel da montagem. Walter Benjamin, em sua obra Teses em Filosofia da História (1969) nos orienta nesse percurso. Benjamin diz que o verdadeiro pensamento histórico é: "captar uma lembrança como ela fulgura num instante de perigo (.....)e para fazer isso é necessário explodir com o continuum da história e descobrir no passado os fragmentos de um futuro descartado ou refutado".

A primeira parte dessa frase é a mais celebre e a que mais se usa em citações, mas é a segunda parte a que agrega um sentido que interessa destacar.

Resgatar a frase de Benjamin é importante por dois motivos:

- a fascinação pelo visual que dela emana ao usar o conceito de fulguração;

- e a idéia de olhar para o passado com vistas ao futuro. 
Nesse sentido, podemos aplicar essa proposta benjaminiana a Georges Méliès, por exemplo, quem, na vertente do artificio e do imaginário, transforma, fascinado pela então nova tecnologia, seus filmes em experimentações de linguagem. Especializa-se no uso de efeitos como "parar a câmera e substituir os objetos" e "sobre impressões feitas na própria câmera" os chamados trick effects (efeitos de trucagem). O objetivo é sempre o de criar uma ilusão próxima da magia. Além disso, adapta seu conhecimento do teatro para o cinema. Constrói cenários em multicamadas, em profundidade de campo, conceitos retomados pelo cinema contemporâneo.

A noção de multicamadas se encontra plenamente desenvolvida em filmes, como por exemplo, O livro de Prospero (1991) e O Livro de Cabeceira (1996), ambos de Peter Greenaway. Os filmes utilizam efeitos digitais que, por sua vez, permitem abrir janelas na imagem com múltiplas ações desenvolvendo-se simultaneamente. A representação dentro da representação.

Em O Livro de Próspero, assim como em Méliès, temos a justaposição de vários espaços em um só, cada um deles em enquadramentos diferentes, quebrando os esquemas narrativos tradicionais que nos conduzem à ilusão. Sempre há algo por detrás da imagem e por detrás da câmera. No caso de O Livro de Cabeceira, além da multiplicidade de espaços e de reenquadramentos, as janelas nos remetem a várias camadas temporais, ou seja, dois tempos passados, o presente filmico e a antecipação de um futuro próximo: (1) um passado distante que representa o livro no qual o filme está baseado - Notes de Chevet (1997) escrito por Sei Shônagon, uma dama de companhia da corte imperial japonesa dos primeiros anos do séc. XI -; (2) o passado intermediário que é a infância da protagonista principal do filme; (3) o presente do filme; e (4) o futuro próximo na janela incrustada no quadro maior. Esses momentos são sempre trabalhados em simultaneidade, rompendo radicalmente a contigüidade temporal (e também espacial) uma vez que as camadas temporais são por vezes trabalhadas em sincronia. 


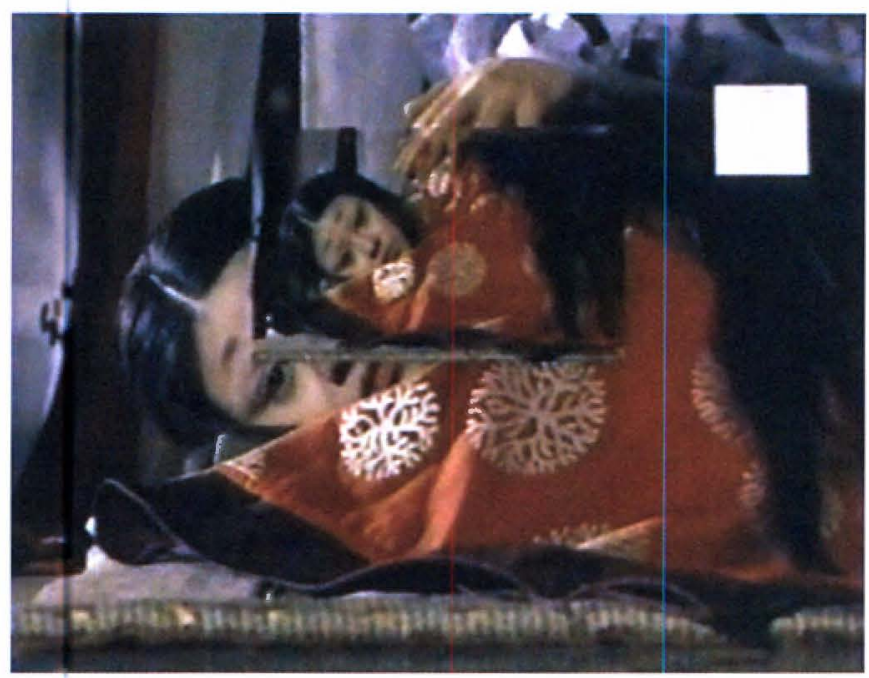

Livro de cabeceira de Peter Greenaway, 1996

A magia, o artificio, o imaginário que acompanha o cinema desde seu início mais remoto (digamos desde a lanterna mágica), são ativados por criadores como Méliès e vão encontrar em distintas etapas do cinema espaços adequados e diferentes de aplicação. Mas, paradoxalmente, André Bazin (crítico e teórico francês que teve seu momento de grande influência) aponta para o fato de rapidamente o cinema se volta para o desenvolvimento de narrativas calcadas na representação da realidade, em paralelo ao artifício, levando o espectador a se deparar com uma perfeita ilusão do mundo real. E sabemos que Bazin encontrou eco na sua leitura de assinalar que há uma obsessão realista que persegue a história do cinema, conjugada a uma obsessão narrativa. De fato, há também, e de maneira forte, a discussão sobre a impressão de realidade.

\section{Impressão da realidade}

O cinema, além de Méliès e de outros semelhantes em sua história, sempre se fez valer da impressão de realidade em função de sua configuração. O cinema é registro, é visão e também narração. Organizando ferreamente esses fatores e, ainda, fazendo 
desaparecer todo rastro dessa organização, o cinema clássico (com sua vocação de transparência), termina por fazer parte do imaginário do espectador. Do espectador identificado, submetido à tela e às ações do filme. Preso na lógica narrativa e nas suas regras de organização. Precisamente há uma dimensão mítica, na qual o cinema se insere, para evidenciar a relação espectador/filme, uma vez que aquele ( o espectador) não pode participar concretamente da ação, nem tocar na imagem que está sendo projetada, mesmo que esteja imerso nas alternativas da narração. A relação do espectador, portanto, dar-se-á no nivel do reflexo, que se apresenta de duas maneiras: (1) no filme propriamente dito, por tratar-se de um relato ficcional de uma ação, remetendo o espectador a um "reflexo da realidade" e (2) na projeção do filme na tela, configurando-se como um espelho do espectador onde ele irá procurar sua identidade.

Tudo isto, que em principio pode parecer abstrato (como falar de identidade e de sujeito espectador) encontra sua formulação concreta na teoria de montagem de Eisenstein que, desenvolvida principalmente entre as décadas de 20 e 30 , antecipa discussões que mantêm sua atualidade pelo fato de sentarem as bases de uma linguagem, no caso, cinematográfica e, por que não, audiovisual. Ele não só teoriza sobre o imaginário e seu reflexo, mas os trabalha nos filmes através da montagem. Isso sem perder de vista o famoso espectador para quem evidencia todas as operações destinadas a emocioná-lo, a sacudi-lo e até influenciá-lo ideologicamente, e não precisamente com um tipo de cinema de impressão de realidade, senão com o máximo artifício.

Dessa maneira, o reflexo deixa de ser, no cinema de Eisenstein, uma "impressão de realidade". A percepção que o espectador tem do filme ultrapassa a noção de "mundo real". Esse significado é produzido pela montagem no momento em que ela irá promover a junção entre o imaginário proposto pela ação interior, a historia narrada, e o imaginário do espectador, chegando assim ao "real" do reflexo. No decorrer da história do cinema, podemos encontrar vários exemplos onde esse procedimento é explicitado, seja em filmes considerados de vanguarda, como em filmes eminentemente clássicos na sua estrutura narrativa. O diferenciador será o estilo de montagem. 
Em Encouraçado Potemkin (1925), Eisenstein nos apresenta uma espécie de comentário de esta relação do "real" (sempre entre aspas com se sabe) e seu reflexo. E o faz na composição de um dos últimos planos da seqüência da escadaria de Odessa. São três planos muito curtos, quase imperceptiveis no ritmo geral da seqüência. A cena é enquadrada em plano próximo e mostra o rosto assustado de um dos perseguidos que, ao mesmo tempo, reflete-se num espelho colocado ao seu lado. Essa duplicidade de imagem cria uma situação ambígua. Não estamos diante de um sintagma como os organizados por Eisenstein sugerindo que um leão se levanta, e muitos outros exemplos famosos de metáfora fílmicas que ele cria aproximando por montagem elementos alheios à diegese. No exemplo do espelho, que se refere à ação propriamente dita, surge a soguinte questão: se o que está sendo visto pelo personagem faz parte de seu imaginário, ou se é uma ação "real". E, em relação ao espectador; se ele "brinca" com sua identidade ao sugerir duas opções dentro da mesma cena.

No entanto, logo em seguida, Eisenstein finaliza a seqüiência com una série de planos muito curtos de uma das mulheres de maior evidência na ação sendo cegada pela espada de um dos cossacos. Agora estamos, assim, diante de uma metáfora: a ambigüidade do plano anterior é substituida pela escuridão provocada pela cegueira que remete o espectador ao sentido repressivo da perseguição. Assim, mesmo que metaforicamente, o olhar do espectador é direcionado através de uma ação concreta (espada cegando olho), para um conceito ideológico (repressão). É importante salientar que, neste caso, a metáfora é colocada como resultante de una ação e, portanto, é conclusiva. Pelo menos muito mais determinante que a ambigüidade da composição anterior que deixa seu sentido em suspenso. 

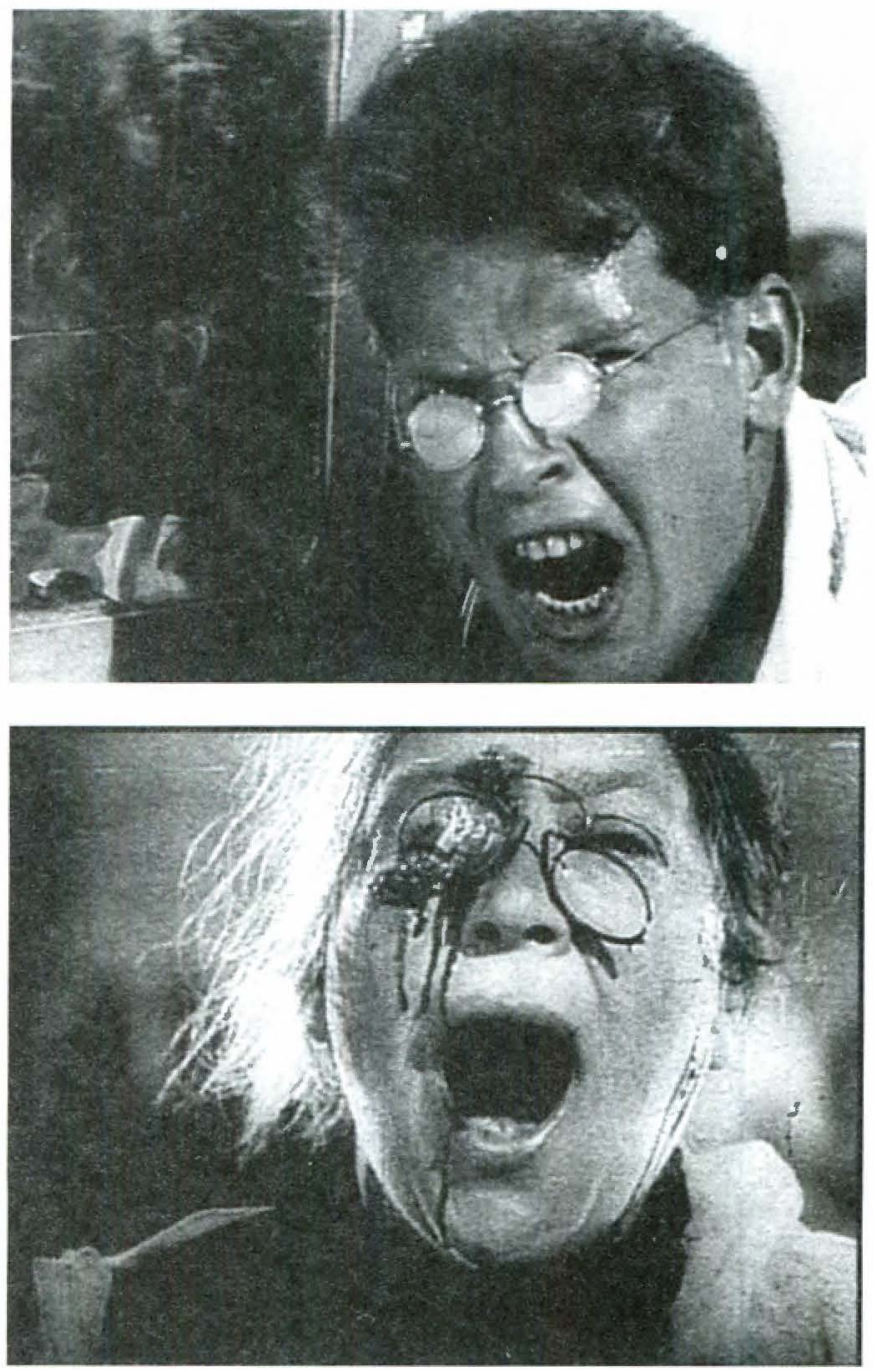

Encouraçado Potemkin de S.M. Eisentein (1925)

A metáfora da cegueira foi utilizada novamente, alguns anos depois, por Buñuel em seu filme Um cão andaluz (1929). O prólogo do filme coloca em discussão o "sentido do olhar" e o papel da imagem, no momento em que o protagonista corta o olho da mulher com uma navalha ao mesmo tempo em que a lua está sendo "cortada" por nuvens. Neste caso, evidencia-se de imediato um tratamento 
metafórico. Ao imaginário do espectador será proposta uma ação abstrata a partir da qual ele terá que encontrar seu ponto de vista.
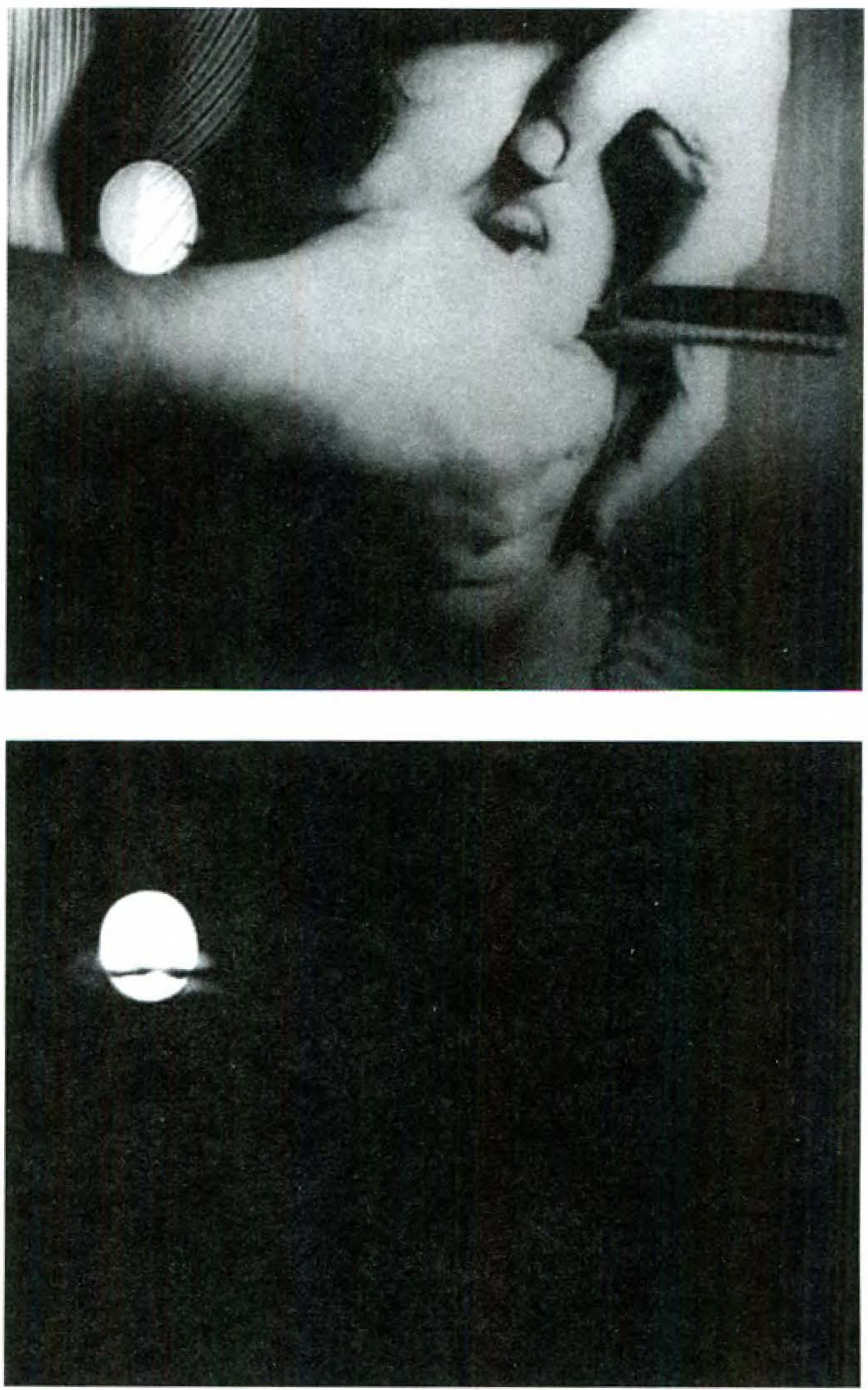

Um cão Andaluz, 1929

Significação $25 \cdot 238$ 
Outro exemplo de referência ao "real" como reflexo é Jean Luc Godard, no filme Les Carabiniers (1963) onde o "real do reflexo" é trabalhado num registro próximo ao de Eisenstein. Trata-se de uma farsa focando os filmes de temática bélica onde dois camponeses são recrutados e vão lutar numa guerra "falsa". Num determinado momento, um dos protagonistas chega a uma cidade e vai ao cinema. O cinema está vazio, mas a escuridão faz com que o personagem tenha dificuldades para achar um assento chocando-se com as poucas pessoas que estão na sala. $\mathrm{Na}$ tela, as imagens que estão sendo projetadas são as da chegada de um trem a uma estação, em referência direta ao filme dos Irmãos Lumière $A$ chegada de um trem à estação (1895) O protagonista do filme de Godard se assusta com o movimento do trem que está vindo do fundo para frente como se fosse ultrapassar a tela e põe o braço diante dos olhos para protegerse de um iminente choque.

Mas o mais significativo dessa seqüência é o fato de ela nos colocar diante de uma situação ambígua uma vez que estamos vendo um filme dentro de um filme. Um dos filmes curtos que está sendo exibido na seqüência da sala de cinema que vemos em Les Carabiniers intitula-se Le bain de la femme du monde. A ação desenrola-se durante a preparação do banho de uma mulher, seu desvestir e a entrada na banheira. Ela anda pelo espaço fílmico chegando a sair de cena. $\mathrm{O}$ "soldado" protagonista tenta acompanhar seus movimentos e. quando ela sai de quadro, ele a busca passando por cima das pessoas que estão sentadas na platéia. Ela volta ao quadro, tira a roupa, mas o enquadramento e o movimento interno da protagonista não permitem que o espectador a veja nua. Finalmente, ela entra na banheira. O "soldado" sobe no palco onde está a tela cinematográfica e pula várias vezes na tentativa de olhar dentro da banheira. Passa a mão pelo rosto refletido na tela numa atitude que mistura um ato de carinho com um ato revestido de sensualidade. A intensidade de seu movimento faz com que a tela se rompa e ele caia num buraco junto com a tela enquanto a cena do banho continua se refletindo na parede atrás da tela. 

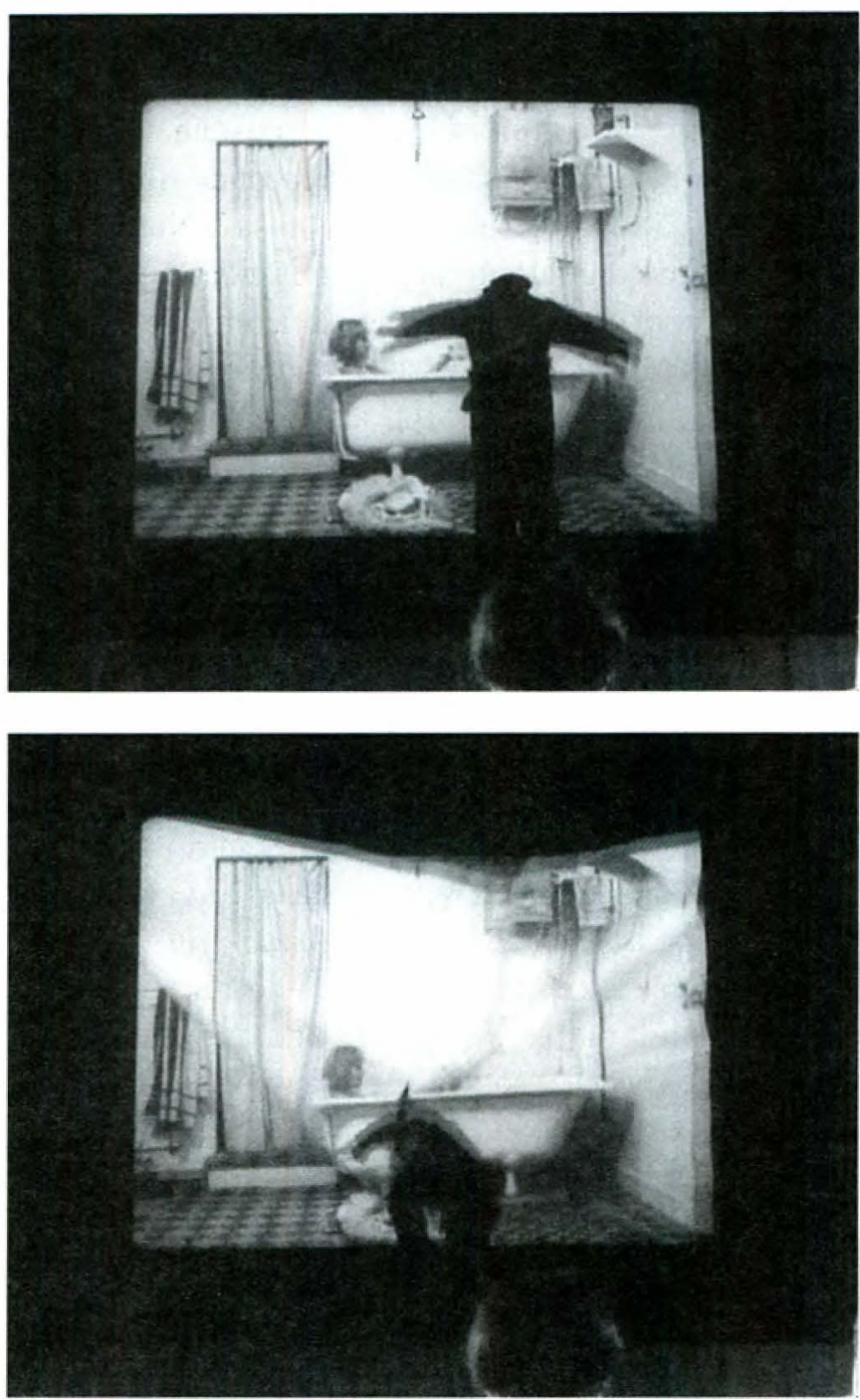

Les Carabiniers de J. L. Godard (1963)

Estamos diante de uma descontrução da relação entre o espectador e o filme que rompe drasticamente, através da estrutura de montagem, com a noção clássica de impressão de realidade. Evidencia-se a ilusão e a idéia de reflexo no momento em que a tela se rompe e o protagonista se desconcerta diante da inexistência da 
imagem "real". Godard retoma de Eisenstein a heterogeneidade do discurso filmico sempre trabalhado por ele de maneira a deixar claro quais as categorias que o formam, indo além na sua desconstrução e passando a considerar o imaginário como real.

Em seu filme $A$ Chinesa (1967), Godard coloca na fala de um dos personagens um postulado tomado de empréstimo do filósofo Alain Badiou e que pode ser considerada a síntese de sua proposta: "Este imaginário não é o reflexo do real dado que é o real deste reflexo". Ainda nas Histoire(s) du cinéma - Fatale beauté (capítulo 1- 1997), Godard, além de levar ao extremo a superposição e a justaposição de imagens e de textos utilizando todas as ferramentas de montagem intra e inter planos, faz também com que o grande poder da montagem adquira um significado de "realidade" com a inserção a cada momento de planos onde o vemos sentado diante de uma máquina de escrever elétrica (como se fosse um regente de orquestra), intercalados com planos de uma "velha" moviola, fazendonos ouvir na trilha sonora os sons originais dos filmes que estão sendo vistos nela.

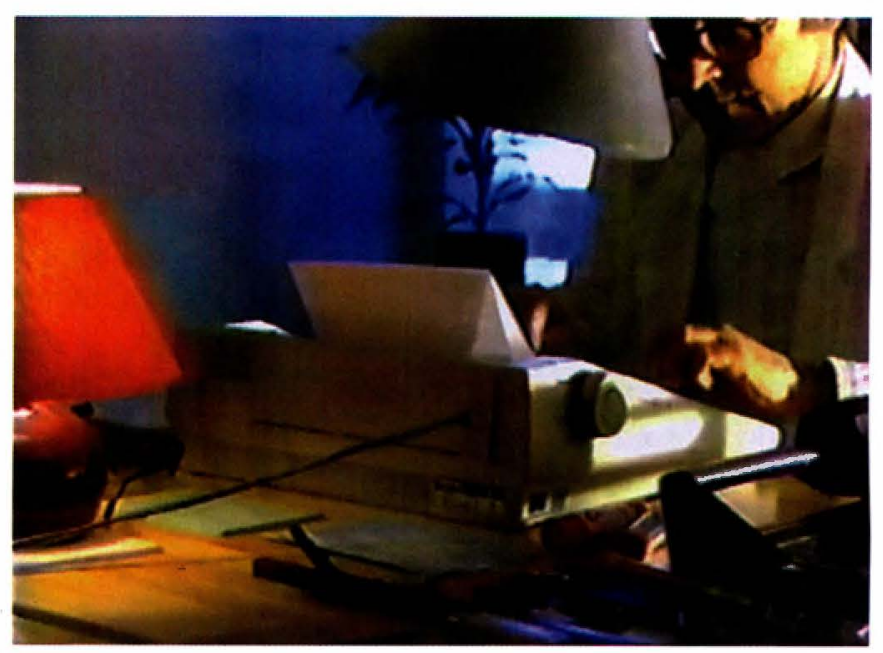




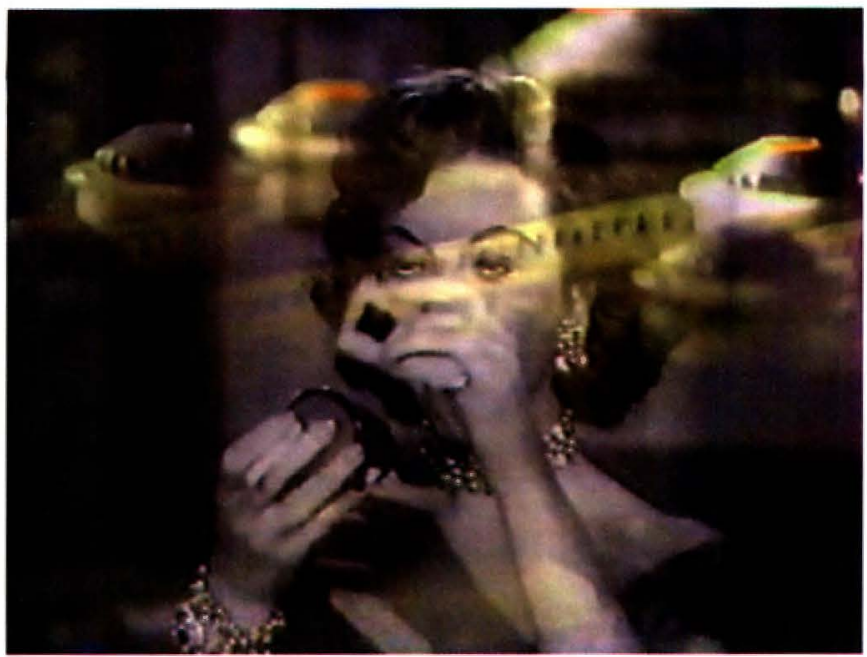

Historie(s) du cinéma - fatale beauté (cap. 1), 1997

No registro do cinema de narrativa clássica também encontramos exemplos de cinema como "real" do reflexo. Um dos mais brilhantes pode ser encontrado no filme de Woody Allen, $A$ Rosa Púrpura do Cairo (1986). A protagonista principal, para fugir de um cotidiano insuportável, vai várias vezes ao cinema assistir a um mesmo filme, até que se apaixona pelo ator e o imagina saindo da tela para conhecê-la. Encontramos idéia similar no filme mudo Sherlock $J r$ (1924), de Buster Keaton, onde o protagonista (ele mesmo) é projecionista de um cinema. Após uma desilusão amorosa adormece ao lado dos projetores e, numa situação onírica, seu corpo se duplica, entra na tela e passa a interagir com a ação que é semelhante à que ele acabara de viver. Os recursos técnicos utilizados são os recorrentes na época, sobreimpressões e mudanças de background, mantendo o movimento do ator em continuidade, somente mudando a cena na qual ele se insere.

$\mathrm{Na}$ fita de Woody Allen, o filme que a protagonista assistia sistematicamente transformou-se em um fato "real", a partir de um processo de identificação com a ação motivada por uma grande carência afetiva. A trucagem, que permite que os atores passem através da tela de maneira convincente, aliada ao estilo de montagem 
narrativa cuja estrutura não diferencia a ação "dentro" e "fora" da tela, possibilita ao espectador acompanhar a ação sem sobressaltos, envolvendo-se e identificando- se.
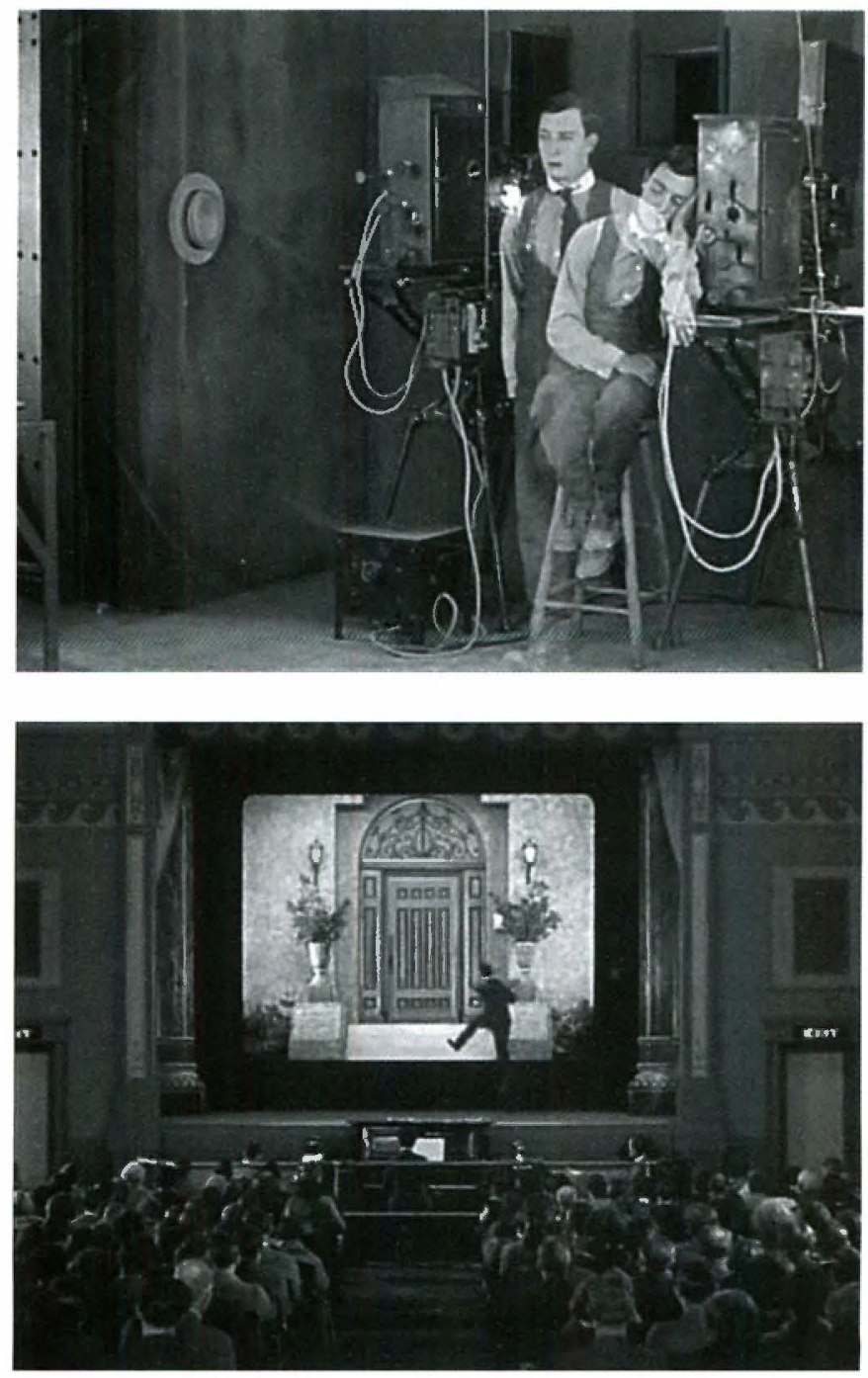

Sherlok Jr. de Buster Keaton, 1924 
Assim sendo, podemos dizer que o cinema permite "criar um real" através do jogo espaço-temporal das imagens e sons, que se completa na relação com o espectador. E aqui se configura a ambivalência do cinema. $\mathrm{O}$ cinema, além de atualizar conteúdos míticos, valoriza tanto a representação da realidade quanto a expressão do imaginário. Sua estrutura cria as condições para que essa realidade seja representada, quando necessário, de maneira verossímil, e contribui decisivamente para construir um espaço cultural do filmico onde os sonhos são perceptiveis e, o que é mais importante ainda, são visíveis.

\section{Cinema narrativo}

Até aqui viemos desenvolvendo exemplos de um tipo de cinema que desconstrói o real e se ocupa de seu reflexo. Ou que se coloca como critica de um cinema dito "real". Mas lembremos que paralelamente ao cinema calcado na experimentação de linguagem temos Griffith que foi o que de fato avançou no modelo de narrativa clássica e predominou no decorrer da evolução da linguagem cinematográfica. Um cinema com estrutura narrativa linear, naturalista, demonstrando respeito pela imagem captada pela câmera. Mas é principalmente na estrutura da narrativa que aperfeiçoa os procedimentos de linguagem como: tipos de enquadramento, dimensão do plano, movimentos internos ao plano e, de maneira mais marcante, a montagem paralela que senta as bases das regras fundamentais da narrativa filmica clássica.

A montagem narrativa recorre a uma estrutura transparente, verossímil, onde o espectador se reconhece. E onde a continuidade, as relações lógicas e as relações miméticas adquirem uma importância significativa. O realismo, na reprodução do real, parecia alcançar, assim, seu grau definitivo de realização. A influência do teatro em Griffith é reconhecida, mas também há uma intenção de trabalhar com uma dramaturgia plástica. Instaura-se um jogo conflitante entre os planos. Os personagens estão sempre em movimento, explorando o espaço do enquadramento como se estivessem tentando encontrar uma saída. A saída está no espaço mental. A criação do espaço no cinema é uma criação mental que surge auxiliada pela montagem. 
A articulação entre os planos é um fenômeno essencial sobre o qual se apóia a teoria da montagem no seu início. A montagem, em GriffIth, é inicialmente uma operação sintagmática realizada através de um processo de fragmentação e seleção de espaços (conflgurando-se uma dimensão temporal) e sobre a fragmentação e seleção do tempo (confIgurando-se uma dimensão espacial). Processos que são aplicações de condições de percepção e de evocação de estímulos. A montagem reproduz as condições de seleção da percepção e da memória que são descontínuos e privilegiam certos espaços-tempo em detrimento de outros menos significativos.

Se no "cinema comercial" vingou o modelo griffithiano em contraposição ao modelo eisensteiniano, Eisenstein, entre outros, continua como referência basicamente para um tipo de cinema de linha experimental, de vanguarda ou documental, alternativo de qualquer forma, e só veio a fulgurar com intensidade novamente a partir da década de $50 \mathrm{e}$, principalmente 60 , quando justamente 0 grande modelo narrativo clássico foi colocado em questão.

\section{O cinema experimental e de vanguarda: Eisenstein}

Voltando a Eisenstein, o foco desta reflexão, é importante salientar que ele fez parte de um momento histórico de grandes mudanças estruturais, sociais, políticas, culturais e artísticas na Rússia, depois União Soviética, e que sua obra filmica está inserida no contexto e reflete, tanto na forma quanto no conteúdo, o momento revolucionário. No entanto, para além da questão política, Eisenstein estava à procura de conferir ao cinema o estatuto de arte e, para isso, era importante identificar seu específico. Assim recorre às outras artes, e às ciências na procura de elementos que pudessem ser transportados para o cinema e, dessa maneira, se constituírem em uma linguagem cinematográfica. Assim dialoga com o teatro de vanguarda, as artes plásticas (cubismo), a literatura (Charles Dickens e James Joyce), a psicologia (Pavlov e o reflexo condicionado/ questões de percepção), a música, a lingüística, o formalismo russo, 
entre outros. A linguagem cinematográfica seria composta pelo conjunto de elementos dos variados códigos, utilizados de maneira a criar uma gramática cinematográfica.

O cinema, visto como uma nova possibilidade de expressão, permitirá a Eisenstein o desenvolvimento de um projeto modernista iniciado por ele nas experiências realizadas no teatro de vanguarda de forte influência construtivista, dirigido por Meyerhold.

Considera que a obra de arte é necessariamente dinâmica e só sé constitui como obra no processo de formação de imagens que ocorre na sensibilidade e na inteligência do espectador, isto é, no caso do cinema, um filme só se transformará em obra de arte ao ser projetado e permitir ao espectador a interação necessária. Esse processo é determinado pela montagem. Não aquela montagem voltada para o específico cinematográfico, mas a que envolve problemas que nos remetem a outros códigos que, no seu conjunto, formularão as necessidades básicas da linguagem cinematográfica. Podemos chamar este estilo de montagem proposto por Eisenstein de Montagem discursiva: montagem significante que utiliza as formas do discurso.

É na maneira como o cinema articula as imagens e os sons e os aproxima que o transforma em discurso. Criam-se novos sentidos, uma nova lógica onde os significados não são transparentes, nascida da associação de fragmentos. Justapõem-se duas realidades: a da vida propriamente dita e a do filme, a do discurso e, ainda dentro do filme, a justaposição de planos determinando novas leituras das imagens. O fragmento é o princípio: cada um tem sua própria significação que, associadas através da montagem, cria novos sentidos. Um plano + um plano $=3^{\circ}$ sentido criado intelectualmente. Os fragmentos não são detalhes da narrativa como na montagem clássica, são representações que vão além da mera conotação realista. Só para dar dois exemplos: no filme Enøouraçado Potemkin (1925) de Eisenstein, o detalhe do olho da mulher sendo cortado por uma espada não é um detalhe realista, assim como em Deus e o Diabo na terra do Sol (1964), de Glauber Rocha, : a mulher matando o beato não é uma ação realista.

O agenciamento dos elementos de maneira discursiva é que encaminhará o espectador a perceber e/ou refletir sobre novos 
significados. O plano como ruptura obriga o espectador a mudar de referências. $\mathrm{E}$ as imagens como fragmentos do mundo, reunificadas através da montagem, criam uma nova unidade. Dessa perspectiva, é importante salientar que a estética do fragmento usa como base o grande plano (detalhe/ primeiríssimo plano). O Cinema clássico também usa o primeiro plano, mas seu significado vai depender da sua inserção dentro da continuidade da narrativa e de sua relação com os outros planos que o acompanham. Na montagem discursiva, esse mesmo plano é usado como atração, como ruptura estética, fora da linha do relato.

O impacto modernista dos anos 20 será compreendido, salvo alguns exemplos particulares, pela cinematografia francesa do fim dos anos $50 \mathrm{e}$, principalmente, dos anos 60.0 movimento, conhecido como Nouvelle Vague, considerava que o argumento de um filme não deve desenvolver-se de maneira lógica, contando uma historia com começo, meio e fim. O espectador deve construir sua própria lógica em função das indicações do autor e do fluxo de seus pensamentos. Assim, opunha-se à narrativa do cinema clássico criando, a partir do conceito de desconstrução, uma nova narrativa que, sem dúvida, se configurou como uma retomada das propostas de montagem de Eisenstein. Godard, como já foi dito, está dentre os mais conhecidos representantes desse reencontro. Nele, o conceito de montagem retoma seu papel de agenciamento de idéias (montagem intelectual). Os conflitos no interior dos enquadramentos e entre os planos são maximizados. Conflitos que segundo Eisenstein são para a arte a melhor e mais ampla definição de montagem. Nesse âmbito, a noção de tempo deixa de ser forçosamente linear e clássica. Rompese a tentativa de considerar o cinema como reflexo do real, e se assume como imaginário do real.

Godard não será o único cineasta a evidenciar em seus filmes conceitos da teoria eisenteiniana. Sabemos como o cinema experimental americano dos anos 60 empregou os métodos de montagem de Eisenstein (Brackage entre outros), e de como foi mantido um diálogo vivo e crescente no decorrer das décadas seguintes. Não podemos deixar de eitar Zbigniew Rybczinski, realizador de Steps (1986), filme que parodia de maneira amarga a 
sequência da escadaria de Odessa de Encouraçado Potemkin. O autor aponta para o uso das novas tecnologias e insere, através do sistema de Chroma Key, um grupo de turistas americanos nos planos originais do filme de Eisenstein, utilizando-se de um recurso tecnológico para criar um diálogo entre passado e presente.
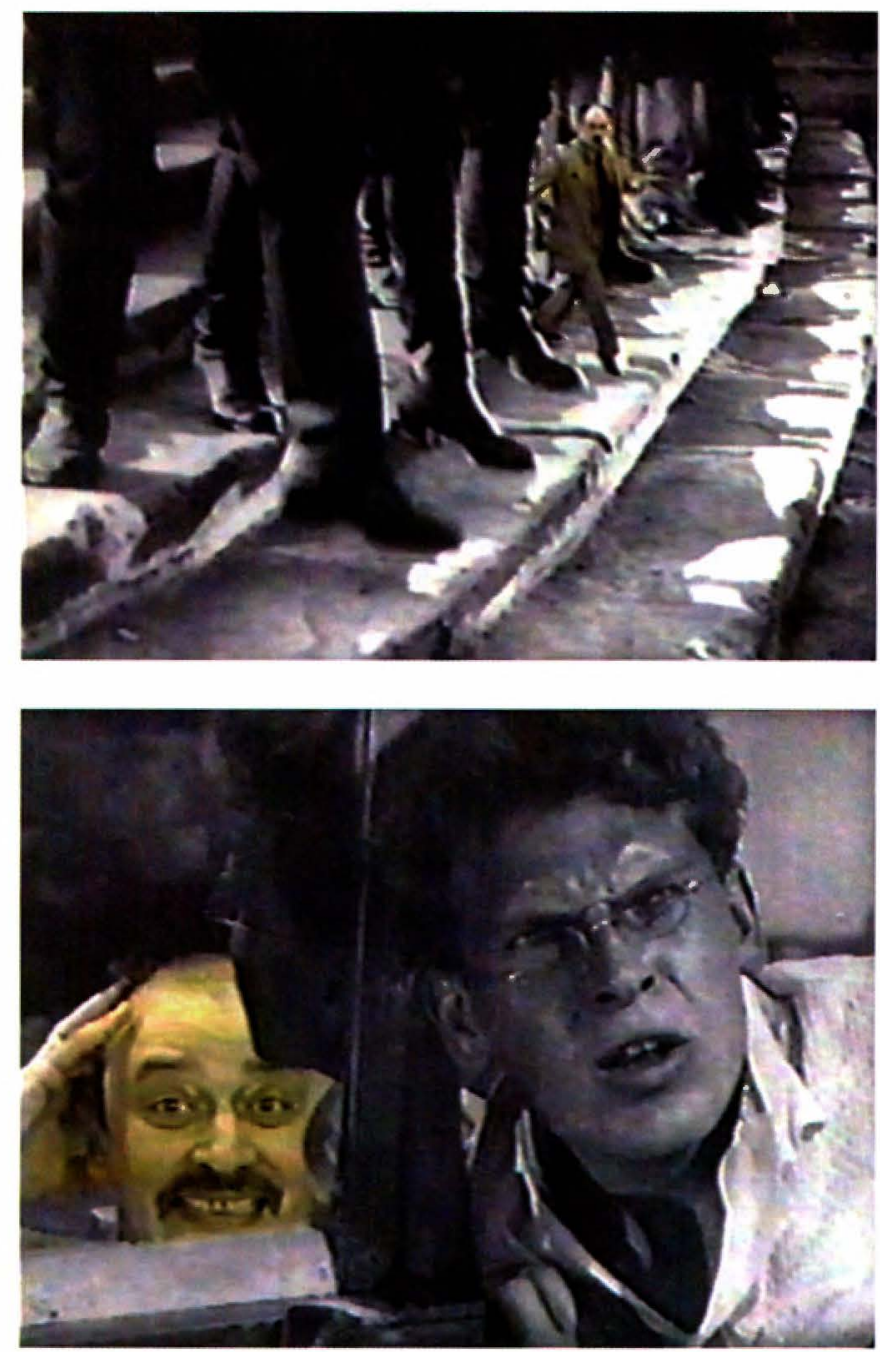

Steps de Zbigniew Rybczinski, 1986 
$\mathrm{Na}$ verdade, através da via do cinema experimental e de vanguarda, as propostas de Eisenstein se mantiveram presentes no decorrer da história do cinema. No entanto, suas marcas estão também no cinema comercial, como citações intertextuais. David Bordwell, em seu livro The Cinema of Eisenstein (1993), faz um rápido traçado das marcas de Eisenstein encontradas na teoria do cinema e na filmografia de alguns cineastas. Cita, entre outros, a Alain Resnais, Godard, Kurosawa, Robert Bresson, Michelangelo Antoníoni e Glauber Rocha como tendo sido influenciados pela sua obra uma vez que, segundo ele, o modo de reflexão eisenteiniano e sua experimentação fílmica, são paradigmas da nova forma de leitura determinada pela literatura e arte contemporâneas.

Jacques Aumont, em uma conferência intitulada Eisenstein chez les autres, proferida em 1996 na Cinemateca Francesa e posteriormente publicada no livro Pour un Cinéma Comparé. Influences et Répétitions (1996), comenta da possibilidade de encontrar nos filmes de John Woo e de Abel Ferrara eventuais etimologias eisensteinianas no vocabulário e na sintaxe da montagem de seus filmes. Mas é em Glauber Rocha que Aumont se detém analisando dois trechos do filme Deus e o Diabo na Terra do Sol. Destaca, basicamente, como Glauber organiza o sistema de contradições (conflitos), um dos elementos básicos da teoria eisensteiniana: contradições entre direções, entre planos fixos e em movimento, entre os planos próximos e gerais, além da mise en scène criada para a cena das escadas numa alusão direta à cena da escadaria de Odessa, do filme Encouraçado Potemkin.

Assim como neste rápido percurso mencionamos momentos centrais na constituição da linguagem cinematográfica, devemos destacar a importância do movimento neo-realista surgido logo após a segunda guerra mundial. Oposto ao modelo eisensteiniano enquanto artifício estético da montagem, o registro da realidade sem efeitos de montagem não implica, no entanto, a volta a uma ilusão da realidade. As influências do neo-realismo italiano também foram determinantes. Se em Glauber rastreamos Eisenstein, em Nelson Pereira dos Santos detectamos a influência do neo-realismo. A cena em Vidas Secas (1963) da família andando pelo sertão pode ser pensada em paralelo 
com a cena de Ladrões de Bicicleta (1948), de Vittorio de Sica, onde o pai e o filho andam em busca da bicicleta roubada.

Em suma, todos os exemplos citados tomam como ponto de partida o sentido da frase de Benjamin, principalmente quando ele propõe uma leitura descontinua do tempo ao apontar para o passado como sendo o lugar onde estão os fragmentos de um futuro descartado ou refutado.

Quando retomamos Eisenstein é porque consideramos que para pensar a montagem como ato criativo temos que proceder ao reencontro com sua teoria e sua prática. É lá nesse passado que encontraremos as bases da contemporaneidade, e na confluência com outros realizadores é que serão impulsionados os avanços de linguagem.

Para Eisenstein o cinema era a montagem, mas a montagem vista de maneira dinâmica, como um conceito que se expande ou que é passivvel de redefinição e que necessariamente dialoga com os outros elementos do filme, é por isso que encontramos seu rastro nos filmes mais significativos das mais variadas cinematografias.

\section{BIBLIOGRAFIA}

AUMONT, Jacques. Eisenstein chez les autres. In: AUMONT, Jacques, (Direction de). Pour un Cinéma Comparé - Influences et Répétitions. Paris: Cinémathèque Française, 1996.

BADIOU, Alain. A autonomia do processo estético. In: BADIOU, Alain. Estruturalismo - antologia de textos teóricos, Lisboa: Coleção Direções, Portugália Editora.

BAZIN, Alain. O Cinema. Ensaios. São Paulo: Editora Brasiliense, 1991.

BENJAMIN, Walter. Theses on the Philosophy of History. Illuminations, 253-264. New York: Schocken Books, 1969.

BORDWELL, David. The Cinema of Eisenstein. London: Harvard University Press, 1993.

EISENTEIN, S.M. O Sentido do Cinema. Rio de Janeiro: Zahar, 1990. 